Discussion Paper No. 04-51

\title{
The Power Law and Dividend Yields
}

Erik Lüders, Inge Lüders-Amann and Michael Schröder

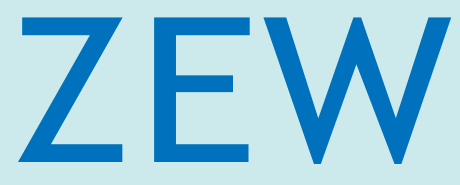

Zentrum für Europäische Wirtschaftsforschung $\mathrm{GmbH}$

Centre for European

Economic Research 
Discussion Paper No. 04-51

\title{
The Power Law and Dividend Yields
}

\author{
Erik Lüders, Inge Lüders-Amann and Michael Schröder
}

Download this ZEW Discussion Paper from our ftp server:

\author{
ftp://ftp.zew.de/pub/zew-docs/dp/dp0451.pdf
}

Die Discussion Papers dienen einer möglichst schnellen Verbreitung von neueren Forschungsarbeiten des ZEW. Die Beiträge liegen in alleiniger Verantwortung der Autoren und stellen nicht notwendigerweise die Meinung des ZEW dar.

Discussion Papers are intended to make results of ZEW research promptly available to other economists in order to encourage discussion and suggestions for revisions. The authors are solely responsible for the contents which do not necessarily represent the opinion of the ZEW. 


\section{Non-Technical Summary}

Recent research suggests that the power law is one of the most universal laws in nature and it also seems to work quite well in economics and finance. In this paper we show that the power law explains relatively well the relationship between the value of broad-based market indices and their dividends. In our analysis "power law" translates into a log-linear relationship between stock prices and dividends in levels.

The theoretical part of the paper gives a motivation for the assumption of the loglinear relationship. This relationship is then estimated for six countries: Canada, France, Germany, Japan, United Kingdom and the United States. The results show that such a relationship actually exists for the major stock markets. The only exception is Japan: there are relatively weak hints of a relationship between stock prices and dividends in the period after the crash of 1990.

The estimated relationships can be interpreted as long-run equilibrium between stock prices and dividends. Deviations from this equilibrium lead to an adjustment process in the direction of a new equilibrium. In Japan, the United Kingdom and the United States the stock price is the variable that adjusts towards the new equilibrium whereas in Canada, France and Germany dividends react.

Of particular interest is the parameter which shows the change of the stock prices related to a change of the dividends. For most of the countries, i.e., France, Germany, the United Kingdom and the United States, this parameter is significantly higher than 1 . This means that, for example, an increase of the dividends of $1 \%$ is accompanied by an increase of the stock prices of more than $1 \%$. For Canada and Japan this parameter is not significantly different from 1 . A parameter higher than 1 is consistent with declining relative risk aversion whereas a parameter equal to 1 is consistent with constant relative risk aversion. Decreasing relative risk aversion means that the risk aversion decreases when wealth increases.

To sum up, the results of the empirical part show that the power law seems to have a solid economic foundation for stock prices and dividends. 


\title{
The Power Law and Dividend Yields
}

\author{
Erik Lüders ${ }^{1}$ \\ Université Laval, Canada \\ Stern School of Business, New York University, USA \\ e-mail: elueders@stern.nyu.edu \\ Inge Lüders-Amann \\ Université Laval, Canada \\ e-mail: inge.lueders-amann@web.de \\ Michael Schröder \\ Centre for European Economic Research (ZEW), Mannheim, Germany \\ e-mail: schroeder@zew.de
}

July 2004

\begin{abstract}
Recent research suggests that the power law is one of the most universal laws in nature and it also seems to work quite fine in economics and finance. In this paper we show that the power law explains extremely well the relationship between the value of broad-based market indices and their dividends. We also show that this relationship is consistent with declining relative risk aversion of the representative investor. Hence, the power law has a solid economic foundation.
\end{abstract}

JEL Classification: G12, G15, E44

Keywords: Power law, stock prices, dividends, co-integration

Corresponding Address:

Dr. Michael Schröder

Centre for European Economic Research (ZEW)

P.O. Box 103443, D-68034 Mannheim, Germany

Phone: +49 6211235 140, Fax +49 6211235 223,

Email: schroeder@zew.de

1 Erik Lüders gratefully acknowledges financial support by the Institut de Finance Mathématique de Montréal. We are also indebted to the Förderkreis of the ZEW for financial support. 


\section{Introduction}

Recent research suggests that the power law is not only a very universal law in natural sciences but that it is also very important in economics and finance. For example, Zipf (1949), Okuyama et al. (1999), Axtell (2001) and Gabaix and Ioannides (2004) show that the size distribution of many entities follows a power law. Gopikrishnan et al. (1999) find evidence for the "power law distribution" of returns. Related findings are provided by Lux (1996). We mention finally the so called "power law of price impact" (see for example Gabaix et al., 2003) which states that the price impact $\Delta p$ of a trade of size $V$ scales approximately as $\Delta p \sim V^{0.5} .^{2}$

In addition to these empirical findings, there is a vast literature on the predictive power of the dividend yield, see for example Lewellen (2003) and references therein. If aggregate dividends follow approximately a random walk, and there is a linear relationship between aggregate dividends and the value of the market portfolio, then market portfolio returns also follow a random walk and dividend yields have no predictive power. However, dividend yields have predictive power for future returns if the market portfolio is not a linear function of aggregate dividends. Recent theoretical work by Franke et al. (1999) and Lüders and Franke (2004) shows that if the representative investor is not constant relative risk averse then the market portfolio is not a linear function of aggregate dividends and therefore it is not governed by a geometric Brownian motion. Recent empirical findings on option prices support the hypothesis on non-constant relative risk aversion. $^{3}$

To sum up, empirical evidence on different economic relationships leads to the conjecture that the price-dividend relationship is also governed by a power law, i.e. $P_{t}=K D_{t}^{\beta}$, where $P_{t}$ is the price of the asset, $D_{t}$ is the dividend and $\beta$ and $K$ are constant parameters. However, an obvious concern would be the lack of a solid economic foundation. Based on a simplified version of Lüders and Franke (2004) we show that the power law is consistent with a representative agent economy with declining relative risk aversion (DRRA). Our empirical analysis for the most important financial markets (Canada, France, Germany, Japan, UK and US) supports our hypothesis.

The paper is organized as follows. In the following section we provide a brief review of the pertinent literature. Section 3 presents the theoretical motivation of the power law. Section 4 presents the empirical results. Section 5 concludes.

2 Instead of continuing this almost endless list we refer to Gabaix et al. (2003).

3 See Aït-Sahalia and Lo (2000), Jackwerth (2000) and Rosenberg and Engle (2002). 


\section{A Brief Literature Review}

Several articles have investigated the relationship between dividends and stock prices. The present value model implies a co-integration relationship between stock prices and dividends, when dividends are difference-stationary and the discount factor is constant. (e.g. Timmermann (1995)). Hence in this case we should be able to find a long run-relationship between the two variables.

Timmermann (1995) finds that even with a volatile discount rate co-integration tests are robust as long as the expected returns process is not strongly persistent.

Campbell and Shiller (1987) find quite persistent deviations from the present value model. Their model fits the data poorly, although at high levels of significance it can not be rejected statistically.

LeRoy and Porter (1981) and Shiller (1981) find that with constant discounting the volatility of the stock price is too high to be explained by movements in future dividends. This is known as the excess volatility hypothesis. Taking into account the non-stationarity of the considered time-series, e.g. Shiller (1987) and West (1988) also find that under the assumption of a constant discount factor, stock price movements cannot be explained by dividend variation alone.

Lee (1995) investigates the effect of permanent and temporary shocks to dividends on stock prices in a present value model. He finds that stock prices initially react similarly strongly to both types of shocks, and hence a large part of stock price fluctuations is due to temporary shocks.

Strauss and Yigit (2001) report, inter alia, co-integration between log-dividends and a log-stock price index for the USA for the two periods from 1926 and 1950, respectively, until 1999.

Nasseh and Strauss (2003) support the present value model using panel cointegration and estimation methods. They find that since the mid 1990s the present value model undervalues stock prices by $43 \%$.

However, these papers do not consider the effect of declining elasticity of the pricing kernel on the relationship between the value of the market index and aggregate dividends. Recent theoretical research by Franke et. al. (1999) and Lüders and Franke (2004), however, suggests that declining elasticity of the pricing kernel can have a significant impact on the characteristics of asset prices. As will be shown in the following section, these papers suggest that in contrast to earlier empirical

studies a non-linear relationship between asset prices and dividends, i.e. $P_{t}=K D_{t}^{\beta}$, with $\beta>1$, does not signify any deviation from equilibrium. We will now present a 
very simplified version of the model of Lüders and Franke (2004) to motivate the power law for the price dividend relationship.

\section{Theoretical Motivation}

Let us assume a simple efficient exchange economy with one traded risky asset. The value of an asset at time $t, P_{t}$, is given by

$$
P_{t}=E_{t}\left(\sum_{h=1}^{\infty} D_{t+h} \frac{\Phi_{t, t+h}}{\left(1+r_{f}\right)^{h}}\right)
$$

where $D_{t+h}$ is the dividend payment at time $t+h, r_{f}$ is the risk-free interest rate and $\Phi_{t, t+h}$ is the pricing kernel to value claims at time $t$ which are due at time $t+h . E_{t}$ is the conditional expectation, where the condition is with respect to all information available at time $t$. Following Lüders and Franke (2004) let us assume that the dividend payments are governed by a geometric random walk, i.e.

$$
D_{t+1}=D_{t} \exp \left(\mu+\sigma \varepsilon_{t+1}\right)
$$

with $\mu$ and $\sigma$ constant coefficients, $\varepsilon_{t+1} \sim N(0,1)$ for all $t$ and that the pricing kernel $\Phi_{t, t+h}$ is a deterministic function of $D_{t+h}$. In this case we can write equation (1) as

$$
P_{t}=D_{t} E_{t}\left(\sum_{h=1}^{\infty} \frac{\exp \left(\mu h+\sigma \sum_{i=1}^{h} \varepsilon_{t+1}\right)}{\left(1+r_{f}\right)^{h}} \frac{\Psi\left(D_{t+h}\right)}{E_{t}\left(\Psi\left(D_{t+h}\right)\right)}\right)
$$

If we further assume that the pricing kernel has constant elasticity, which is equivalent to constant relative risk aversion of the representative investor, i.e. we assume $\Psi\left(D_{t+h}\right)=\left(D_{t+h}{ }^{\delta}\right)$, then equation (2) simplifies to $P_{t}=D_{t} A_{t}$, where $A_{t}$ is a deterministic function of $r_{f}, \mu$ and $\sigma$ since all $D_{t+h}$ are lognormally distributed. In this case, the asset price follows a geometric random walk. This is the well known result that constant relative risk aversion is consistent with the market portfolio being governed by a geometric random walk. ${ }^{4}$ If we assume, instead, that the pricing

4 See Franke et al. (1999) and Lüders and Franke (2004). 
kernel $\frac{\Psi\left(D_{t+h}\right)}{E_{t}\left(\Psi\left(D_{t+h}\right)\right)}$ is given by $\frac{D_{t+h}^{\beta-1}}{C}$ where $C$ is a constant parameter, then we get that $P_{t}=K D_{t}^{\beta}$.

If $\beta$ is equal to 1 , then we have the case of constant elasticity of the pricing kernel. If the pricing kernel has declining [increasing] elasticity, then the risk premium decreases [increases] with increasing $D_{t}$ and this leads to a higher [smaller] associated increase of $P_{t}$ than under constant elasticity of the pricing kernel. Hence the elasticity of $P_{t}$ with respect to $D_{t}$ is higher [smaller] than 1 , i.e. $\beta>1[\beta<1] .{ }^{5}$ While the analysis of Lüders and Franke (2004) reveals that the relationship between asset prices and dividends in general is much more complicated than this, such a rough approximation of the relationship seems at least appropriate for a first empirical analysis.

\section{Empirical Analysis}

We use the Thomson Financial Datastream Total Market Indices and the corresponding dividend indices for Canada, France, Germany, Japan, the UK and the US. Hence, we consider six of the most important stock markets in the world. We use monthly data for the time period January 1973 until October 2003. All indices are price indices.

Instead of estimating $P_{t}=K D_{t}^{\beta}$ we estimate

$\ln P_{t}=\alpha+\beta \ln D_{t}+\varepsilon_{t}$,

where $\varepsilon_{t}$ is white noise and $\alpha=\ln K$.

A precondition for estimating equation (3) is that log-stock prices and log-dividends are co-integrated. Hence, our first step is to analyze if there is a co-integrating relationship between the time series of log-prices and log-dividends. This is the case if log-stock prices as well as log-dividends are integrated of order 1 (unit root process) and if there exists a linear relationship between these two variables which is integrated of order $0 .{ }^{6}$

5 For a detailed derivation see Lüders and Franke (2004).

6 For a discussion of the concept of co-integration see e.g. Engle and Granger (1987) or Hamilton (1994). 
We use ADF-tests and KPSS-tests to test for non-stationarity. Then, we test for weak exogeneity and test for co-integration next. The last step will be to estimate equation (3) and to test for the long-run parameters $\alpha$ and $\beta$.

\subsection{Results of the (Non-) Stationary-Tests}

We use the Augmented Dickey Fuller (ADF)-test and the KPSS test to analyze whether the logarithmic variables are stationary or integrated. ${ }^{7}$ The ADF-test takes the unit root as null hypothesis, hence, the rejection of the null states that the variable is stationary. For each of the six countries the log-dividend and log-stock index series are analyzed. Table 1 shows the results for the levels and the first differences of the time series. The number of lags has been chosen by minimizing the Akaike Information Criterion. The figures in columns 4 and 5 show the estimates for the ADF-tests in case of using either a constant or a constant and a time-trend. ${ }^{8}$

Table 1 gives the results for the total data sample from January 1973 until November 2003. As the Japanese stock index changed dramatically at the beginning of 1990 we also analyze the Japanese time series before and after January 1990. The results of these additional tests are shown in Table 2.

The ADF-tests show that most of the time series are non-stationary in levels and stationary in first differences. But there are some remarkable differences. The stock indices of Canada and the USA appear to be stationary in levels as well as the dividend series of France and the UK.

The KPSS-test has the null-hypothesis „stationarity“. The test uses the regression of the time series to be analyzed against a constant or a constant and a time trend. An essential part of the test statistic is the consistent estimation of the variance of the residual time series. According to Hobijn et al. (1998) the automatic lag selection procedure developed by Newey and West (1994) in combination with the Quadratic spectral kernel considerably improves the performance of the test compared to the original KPSS test. Thus, we apply this lag selection procedure in our tests.

Columns 6 and 7 of Table 1 show the results of the KPSS-tests. Almost all of the time series seem to be non-stationary in levels. Only the UK dividend series appears to be I(2) as the null-hypothesis is rejected for the differenced series. This is a strong contradiction of the result of the ADF-test as this test characterizes the UK dividend series as stationary in levels. The KPSS-test also contradicts the outcomes of the ADF-tests regarding the Canadian and US stock indices and the French dividend series.

7 The KPSS-test has been developed by Kwiatkowski et al. (1992).

8 The results for the ADF-tests in case of using neither a constant nor a trend are not reported as these results do not change the conclusions. 
The time series for Japan seem to be I(1) for the total period under consideration. For the two sub-periods, Jan. 1973 - Jan. 1990 and Febr. 1990 - Nov. 2003, the results are less clear (see Table 2). According to the ADF-test the stock index and the dividend series are I(1) in the first period. In the second period the dividends seem to be I(2) and the stock prices I(0). According to the KPSS-test the dividends (first period) and stock prices (second period) are stationary whereas the series are I(1) during the other periods.

The following co-integration test is based on the assumption that all time series are I(1). For the total time period 1973 - 2003 this assumption is at least supported by the KPSS-tests. The only exception is the UK dividend series for which the results provide no clear indication of I(1)-behavior. For this series and the Japanese series in the two sub-periods the assumption of I(1) is only tentative and the respective results on co-integration and the long-run parameters should be interpreted with caution.

\subsection{Results of the Co-integration Tests}

We use the bivariate ECM test of Banerjee et al. (1998). As shown by Banerjee et al. this test is superior to alternative single-equation co-integration tests, e.g. the EngleGranger (1987)-approach. The test is based on the following equation:

$$
d Y_{t}=\alpha+\sum_{i=0}^{p 1} \beta_{i} d X_{t-i}+\sum_{i=1}^{p 2} \gamma_{i} d Y_{t-i}+\delta Y_{t-1}+\varphi X_{t-1}+\varepsilon_{t}
$$

The null-hypothesis of no co-integration is rejected if the parameter $\delta$ is significantly negative. This parameter is equal to the adjustment coefficient and measures the speed by which the disequilibrium is reduced. The lagged differences of $X_{t}$ and $Y_{t}$ are included to avoid autocorrelation of the residuals. The test has been performed in both directions, i.e., $Y_{t}$ is either the log-dividend series or the log-stock index.

As an additional requirement to apply the test, the $X_{t}$ series has to be weakly exogenous. The result of these tests is that the null-hypothesis „not weakly exogenous" could not be rejected in any case. This means that the dividends $\left(X_{t}\right)$ in equation (4) are weakly exogenous for the stock indices $\left(Y_{t}\right)$ and vice versa. As a consequence the co-integration test of Banerjee et al. (1998) can be performed. ${ }^{9}$

Tables 3a and 3b show the estimates for the parameter $\delta$ as well as the t-value (in brackets). We have used the simulated critical values of Banerjee et al. (1998, Table I, p. 276) for the significance test. The structure of equation (4), i.e. the lag lengths $p 1$ and $p 2$, has been chosen using the Akaike Information Criterion.

9 Details on the results of the exogeneity-tests will be sent by the authors upon request. 
Table 3a shows the results for the log-dividends as left-hand-side variable $Y_{t}$, whereas Table $3 \mathrm{~b}$ shows the results for the case „Y $Y_{t}=$ log-stock index“. The cointegration tests have been performed for the total period 1973 - 2003. For Japan also the two sub-periods, Jan. 1973 - Jan. 1990 and Febr. 1990 - Nov. 2003, have been analyzed.

Co-integration between dividends and stock indices has been found for all countries with the only exception of Japan for which co-integration seems to exist only in the second sub-period. For France and Japan the null-hypothesis of "no co-integration" could only be rejected at the $10 \%$ significance level.

In Canada, France and Germany the dividends adjust to the disequilibrium, whereas in Japan, UK and USA the stock index reacts. The adjustment parameter $\delta$ is smallest for USA and France. A full adjustment to a disequilibrium takes about 44 to 50 months, respectively. In UK and Japan the adjustment period is shortest with about 13 to 15 months. The adjustment periods for Canada (37 months) and Germany (26 months) are in-between.

\subsection{Estimation and Test of the Long-Run Parameters}

The parameters of the long-run equation (3) can be estimated using the following ECM equation (where $\Delta$ indicates the first difference of the variable):

$$
\Delta Y_{t}=\sum_{i=-p}^{p} \kappa \Delta X_{t-i}+\sum_{i=1}^{p} \gamma\left(Y_{t-i}-\lambda X_{t-i}-\mu\right)+\varepsilon_{t}
$$

This equation for estimating and testing the long-run parameters has been suggested, for example, by Inder (1993). For a further discussion see also Mills (1999, chapter 7.3).

Equation (5) is estimated by nonlinear least squares. With regard to the results of the co-integration tests equation (5) is estimated for Japan, the UK and the USA using the log-stock index as $Y_{t}$ and the log-dividend series as $X_{t}$. This yields the parameters of interest regarding equation (3): $\beta=\lambda$. For Canada, France and Germany $Y_{t}$ is the log-dividend series and $X_{t}$ is the log-stock index because the co-integration tests exhibited that the dividends adjust to a new equilibrium and not the stock prices. For these countries the parameter $\beta$ of equation (3) is just the inverse of the estimated $\lambda$ parameter of equation (5).

Tables $4 \mathrm{a}$ and $4 \mathrm{~b}$ show the parameters of the long-run equation ( $\mu$ and $\lambda$ ) and the results of the test of the null-hypotheses: $\lambda=0$ as well as $\lambda=1$. The result of the latter test is given in brackets. The t-statistics have been corrected for heteroskedasticity and autocorrelation using the Newey-West (1987) approach. The lag length $p$ of equation (5) has been chosen according to the Akaike Information Criterion. 
The $\lambda$-parameter is for all countries significantly different from zero. For most of the countries this parameter is also significantly different from 1 . Only for Canada and Japan the null-hypothesis $\lambda=1$ could not be rejected at usual significance levels. As for Canada, France and Germany the parameter of interest is the inverse of the estimated $\lambda$-parameter it can be concluded that $\beta$ is significantly higher than 1 for France, Germany, the UK and the USA. Moreover, $\beta$ being significantly higher than 1 for most of the countries under consideration strengthens the case made by, for example, Franke et al. (1999) and Lüders and Franke (2004) that the pricing kernel seems to have declining elasticity.

\section{Conclusion}

This paper shows that the well known power law explains the relationship between the value of market indices and aggregate dividends remarkably well. We derive this power law from a simplified version of Lüders and Franke (2004). The theoretical analysis allows us to relate the coefficients to the utility function of the representative investor. Consistent with Franke et al. (1999) and Lüders and Franke (2004) our results suggest that at least during the last 20 years the representative investor had declining relative risk aversion. 


\section{Appendix:}

Table 1: Results of the ADF-Test $\left(\mathrm{H}_{0}\right.$ : Non-Stationarity) and KPSS-Test ( $\mathrm{H}_{0}$ : Stationarity)

\begin{tabular}{|c|c|c|c|c|c|c|}
\hline & & \multicolumn{3}{|c|}{ ADF Test } & \multicolumn{2}{|c|}{ KPSS Test } \\
\hline Country & Variable & Lags & Constant & $\begin{array}{l}\text { Constant } \\
\text { and Trend }\end{array}$ & Constant & $\begin{array}{l}\text { Constant and } \\
\text { Trend }\end{array}$ \\
\hline \multirow[t]{4}{*}{ Canada } & Dividends (level) & 8 & 0.07 & -2.18 & $2.99 * * *$ & $0.251^{* * *}$ \\
\hline & (differences) & 7 & $-7.16^{* * *}$ & $-7.19 * * *$ & 0.091 & 0.076 \\
\hline & Stock Index (level) & 0 & -0.12 & $-3.16^{*}$ & $3.16^{* * *}$ & $0.144^{*}$ \\
\hline & (differences) & 0 & $-18.23^{* * *}$ & $-18.22 * * *$ & 0.074 & 0.047 \\
\hline \multirow[t]{4}{*}{ France } & Dividends (level) & 15 & -1.25 & $-3.31 *$ & $3.22 * * *$ & $0.265 * * *$ \\
\hline & (differences) & 14 & $-3.56 * * *$ & $-3.64 * *$ & 0.115 & 0.037 \\
\hline & Stock Index (level) & 3 & -0.47 & -3.05 & $3.18 * * *$ & $0.149 * *$ \\
\hline & (differences) & 2 & $-10.03^{* * *}$ & $-10.02 * * *$ & 0.080 & 0.082 \\
\hline \multirow[t]{4}{*}{ Germany } & Dividends (level) & 6 & -0.24 & -1.97 & $2.98 * * *$ & $0.500 * * *$ \\
\hline & (differences) & 5 & $-7.80 * * *$ & $-7.81 * * *$ & 0.111 & 0.083 \\
\hline & Stock Index (level) & 1 & -0.61 & -2.52 & $3.08 * * *$ & $0.143^{*}$ \\
\hline & (differences) & 0 & $-17.99 * * *$ & $-17.97 * * *$ & 0.089 & 0.088 \\
\hline \multirow[t]{4}{*}{ Japan } & Dividends (level) & 3 & -2.11 & -1.80 & $2.54 * * *$ & $0.741^{* * *}$ \\
\hline & (differences) & 2 & $-8.60 * * *$ & $-8.67 * * *$ & 0.079 & 0.08 \\
\hline & Stock Index (level) & 0 & -1.32 & -0.50 & $2.35 * * *$ & $0.664 * * *$ \\
\hline & (differences) & 0 & $-18.01 * * *$ & $-18.08 * * *$ & 0.300 & $0.123 *$ \\
\hline \multirow[t]{4}{*}{ UK } & Dividends (level) & 16 & $-2.59 *$ & 0.12 & $3.19 * * *$ & $0.750 * * *$ \\
\hline & (differences) & 15 & $-3.14 * *$ & $-4.16 * * *$ & $1.44 * * *$ & $0.190 * *$ \\
\hline & Stock Index (level) & 3 & -0.94 & -2.00 & $3.20 * * *$ & $0.427 * * *$ \\
\hline & (differences) & 2 & $-10.50 * * *$ & $-14.22 * * *$ & 0.119 & 0.091 \\
\hline \multirow[t]{4}{*}{ USA } & Dividends (level) & 9 & $-3.94 * * *$ & -1.71 & $3.20 * * *$ & $0.663 * * *$ \\
\hline & (differences) & 8 & $-4.10 * * *$ & $-18.34^{* * *}$ & $1.02^{* * *}$ & 0.056 \\
\hline & Stock Index (level) & 0 & 0.15 & $-3.15^{*}$ & $3.21 * * *$ & $0.327 * * *$ \\
\hline & (differences) & 0 & $-18.85^{* * *}$ & $-18.86 * * *$ & 0.222 & $0.145 *$ \\
\hline
\end{tabular}

Notes: All variables in logarithms. Period: Jan. 1973 - Nov. 2003. Significance levels: $* * *=1 \%$, $* *=5 \%, *=10 \%$. ADF-Tests: Critical values of MacKinnon (1991). Lags according to the Akaike Information Criterion. KPSS-Tests (applying the Quadratic spectral kernel): Lags according to the automatic lag selection procedure of Newey/West (1994). 
Table 2: Results of the ADF-And KPSS-Tests For Japan in Different Time Periods

\begin{tabular}{|c|c|c|c|c|c|c|}
\hline & & \multicolumn{3}{|c|}{ ADF Test } & \multicolumn{2}{|c|}{ KPSS Test } \\
\hline Period & Variable & Lags & Constant & $\begin{array}{l}\text { Constant } \\
\text { and Trend }\end{array}$ & Constant & $\begin{array}{l}\text { Constant } \\
\text { and Trend }\end{array}$ \\
\hline \multirow{4}{*}{$\begin{array}{l}\text { 1973:1 - } \\
1990: 1\end{array}$} & Dividends (level) & 0 & -0.85 & -2.78 & $2.08 * * *$ & 0.107 \\
\hline & (differences) & 0 & $-13.54 * * *$ & $-13.51 * * *$ & 0.047 & 0.041 \\
\hline & Stock Index (level) & 0 & 1.57 & -2.74 & $1.94 * * *$ & $0.466 * * *$ \\
\hline & (differences) & 0 & $-13.34 * * *$ & $-13.67 * * *$ & $0.606 * *$ & 0.082 \\
\hline \multirow{4}{*}{$\begin{array}{l}\text { 1990:2 - } \\
\text { 2003:11 }\end{array}$} & Dividends (level) & 6 & -2.10 & -2.04 & $1.42 * * *$ & $0.144^{*}$ \\
\hline & (differences) & 5 & -2.11 & -1.20 & 0.200 & $0.159 * *$ \\
\hline & Stock Index (level) & 0 & $-2.80^{*}$ & -2.98 & $0.744^{* * *}$ & 0.111 \\
\hline & (differences) & 0 & $-12.44 * * *$ & $-12.44 * * *$ & 0.098 & 0.071 \\
\hline
\end{tabular}

Notes: All variables in logarithms. Significance levels: $* * *=1 \%, * *=5 \%$, $*=10 \%$. ADF-Tests: Critical values of MacKinnon (1991). Lags according to the Akaike Information Criterion. KPSSTests (applying the Quadratic spectral kernel): Lags according to the automatic lag selection procedure of Newey/West (1994).

Table 3a: Results of the Co-Integration Test When $Y_{t}=$ Log-Dividends, $X_{t}=$ Log-Stock Index in Equation (4), Estimates for parameter $\delta$

\begin{tabular}{|l|c|c|c|}
\hline Country & Lags $p 1, p 2$ & Parameter Value & T-Statistic \\
\hline Canada & 0,2 & -0.027 & $-3.42^{* *}$ \\
\hline France & 0,0 & -0.020 & $-3.07^{*}$ \\
\hline Germany & 0,1 & -0.039 & $-4.00^{* * *}$ \\
\hline $\begin{array}{l}\text { Japan (from Febr. } \\
1990 \text { on) }\end{array}$ & 0,0 & -0.027 & -1.31 \\
\hline UK & 0,0 & -0.0006 & -0.11 \\
\hline USA & 0,0 & -0.0015 & -1.05 \\
\hline
\end{tabular}

Notes: Period: Jan. 1973 - Nov. 2003. Significance levels: $* * *=1 \%$, $* *=5 \%, *=10 \%$. Application of the critical values of Banerjee et al. (1998, Table I, p. 276). Lag lengths $p 1$ and $p 2$ according to the Akaike Information Criterion. HAC-corrected t-statistics according to Newey/West (1987). 
Table 3b: Results of the Co-Integration Test When $Y_{t}=$ Log-Stock Index, $X_{t}=$ LogDividends in Equation (4), Estimates for parameter $\delta$

\begin{tabular}{|l|c|c|c|}
\hline Country & Lags $p 1, p 2$ & Parameter Value & T-Statistic \\
\hline Canada & 0,0 & -0.014 & -0.98 \\
\hline France & 0,1 & -0.22 & -1.95 \\
\hline Germany & 0,0 & 0.004 & 0.34 \\
\hline $\begin{array}{l}\text { Japan (from Febr. } \\
1990 \text { on) }\end{array}$ & 1,0 & -0.079 & $-3.12^{*}$ \\
\hline UK & 0,1 & -0.066 & $-4.33^{* * *}$ \\
\hline USA & 0,0 & -0.023 & $-3.31^{* *}$ \\
\hline
\end{tabular}

Notes: Period: Jan. 1973 - Nov. 2003. Significance levels: $* * *=1 \%$, $* *=5 \%$, $*=10 \%$. Application of the critical values of Banerjee et al. (1998, Table I, p. 276). Lag lengths $p 1$ and $p 2$ according to the Akaike Information Criterion. HAC-corrected t-statistics according to Newey/West (1987).

Table 4a: Long-Run Parameters $\left(Y_{t}=\right.$ Log-Dividends, $X_{t}=$ Log-Stock Index in Equation (5))

\begin{tabular}{|l|c|c|c|}
\hline \multirow{2}{*}{ Country } & \multirow{2}{*}{ Lag Length $p$} & \multicolumn{2}{|c|}{ Parameter Values and Parameter Tests } \\
\cline { 3 - 4 } & & $\mu$ & $\lambda(=1 / \beta)$ \\
\hline Canada & 1 & $-1.16^{*}$ & $0.60^{* * *}(\lambda=1$ : not rejected $)$ \\
\hline France & 2 & $-1.11^{* *}$ & $0.69 * * *(\lambda=1: *)$ \\
\hline Germany & 2 & $-1.48^{* * *}$ & $0.60^{* * *}(\lambda=1: * *)$ \\
\hline
\end{tabular}

Notes: Period: Jan. 1973 - Nov. 2003. Significance levels: $* * *=1 \%, * *=5 \%, *=10 \%$. Lag length according to the Akaike Information Criterion. HAC-corrected t-statistics according to Newey/West (1987).

Table 4b: Long-Run Parameters $\left(Y_{t}=\right.$ Log-Stock Index, $X_{t}=$ Log-Dividends in Equation (5))

\begin{tabular}{|l|c|c|c|}
\hline Country & Lag Length $p$ & \multicolumn{2}{|c|}{ Parameter Values and Parameter Tests } \\
\cline { 2 - 4 } & 1 & $\mu$ & $\lambda(=\beta)$ \\
\hline $\begin{array}{l}\text { Japan (from } \\
\text { Febr. 1990 } \\
\text { on) }\end{array}$ & 1 & $4.30^{* * *}$ & $1.47^{* * *}(\lambda=1:$ not rejected) \\
\hline UK & 1 & $2.57^{* * *}$ & $1.19^{* * *}(\lambda=1: * *)$ \\
\hline USA & $1.99^{* * *}$ & $1.92^{* * *}(\lambda=1: * * *)$ \\
\hline
\end{tabular}

Notes: Period: Jan. 1973 - Nov. 2003. Significance levels: $* * *=1 \%, * *=5 \%$, $*=10 \%$. Lag length according to the Akaike Information Criterion. HAC-corrected t-statistics according to Newey/West (1987). 


\section{Literature}

Aït-Sahalia, Y., A.W. Lo (2000). “Nonparametric Risk Management and Implied Risk”, Journal of Econometrics 94, 9-53.

Axtell, R.,(2001). “Zipf Distribution of U.S. Firm Sizes”, Science 293, 1818-1820.

Banerjee, A., J.J. Dolado and R. Mestre (1998). "Error-Correction Mechanism Tests for Co-integration in a Single-Equation Framework”, Journal of Time Series Analysis 19, 267-283.

Campbell, J. and R. Shiller, (1987). "Co-integration and Tests of Present Value Models”, Journal of Political Economy 95, 1062-1088.

Engle, R. and C. Granger, (1987). "Co-integration and Error Correction: Representation, Estimation and Testing”, Econometrica 55, 251-276.

Franke, G., R.C. Stapleton and M.G. Subrahmanyam (1999). "When are Options overpriced? The Black-Scholes Model and Alternative Characterisations of the Pricing Kernel”, European Finance Review 3, 79-102.

Gabaix, X., P. Gopikrishnan, V. Plerou and H.E. Stanley, (2003). “A Theory of Large Fluctuations in Stock Market Activity”, MIT Department of Economics Working Paper No. 03-30.

Gabaix, X. and Y. Ioannides, (2004). "The Evolution of the City size Distribution”, Handbook of Urban and Regional Economics, Vol. IV: Cities and Geography, (eds.) J. V. Henderson and J. F. Thisse, forthcoming.

Gopikrishnan, P., V. Plerou. L. Amaral, M. Meyer and H.E. Stanley, (1999). "Scaling of the Distribution of Fluctuations of Financial Market Indices", Physical Review E 60, 5305-5316.

Hamilton, J., (1994), “Time Series Analysis”, Princeton University Press, Princeton.

Hobijn, B., P.H. Franses and M. Ooms, (1998). "Generalisations of the KPSS-Test for Stationarity”, Working Paper No. 9802/A, Econometric Institute, University of Rotterdam.

Inder, B., (1993). "Estimating Long-Run Relationships in Economics”, Journal of Econometrics 57, 53-68.

Jackwerth, J.C., (2000). "Recovering Risk Aversion from Option Prices and Realized Returns”, Review of Financial Studies 13, 433-451.

Kwiatkowski, D., P.C.B. Phillips, P. Schmidt and Y. Shin, (1992). "Testing the Null Hypothesis of Stationarity against the Alternative of a Unit-Root: How sure are we that economic series have a unit root?”, Journal of Econometrics 54, 159-178.

LeRoy, S. and Porter, R., (1981). “The Present Value Relation: Tests Based on Variance Bounds”, Econometrica 49, 555-577. 
Lee, B., (1995). “The Response of Stock Prices to Permanent and Temporary Shocks to Dividends”, Journal of Financial and Quantitative Analysis, 30, 122.

Lewellen, (2003). "Predicting Returns with Financial Rations”, forthcoming Journal of Financial Economics.

Lüders, E. and G. Franke, (2004). "Why Do Asset Prices Not Follow Random Walks?” Discussion Paper, Center of Finance and Econometrics, University of Konstanz, Germany.

Lux, T., (1996). "The Stable Paretian Hypothesis and the Frequency of Large Returns: An Examination of Major German Stocks”, Applied Financial Economics 6, 463-475.

MacKinnon, J., (1991). “Critical Values for Co-Integration Tests”, in R.F. Engle and C.W.J. Granger (eds.), Long-Run Economic Relationships, Oxford: Oxford University Press, 267-276.

Mills, T.C., (1999). “The Econometric Modelling of Financial Time Series”, Cambridge: Cambridge University Press, 2nd edition.

Nasseh, A. and J. Strauss, (2003). "Stock Prices and the Dividend Discount Model: Did their Relationship break down in the 1990s?” The Quarterly Review of Economics and Finance, forthcoming.

Newey, W.K. and K.D. West (1987). "A simple positive semi-definite heteroskedasticity and autocorrelation consistent covariance matrix", Econometrica 55,703-708.

Newey, W.K. and K.D. West, (1994). “Automatic lag selection in covariance matrix estimation”, Review of Economic Studies 61, 631-653.

Okuyama, K., M. Takayasu and H. Takayasu, (1999). “Zipf's Law in Income Distribution of Companies”, Physica A 269, 125-131.

Rosenberg, J. V. and R. F. Engle, (2002). “Empirical Pricing Kernels”, Journal of Financial Economics 64, 341-372.

Shiller, R., (1981). "Do Stock Prices move too much to be Justified by Subsequent Changes in Dividends?”, American Economic Review 71, 421-436.

Strauss, J. and T. Yigit (2001). "Present Value Model, Heteroskedasticity and Parameter Stability Tests”, Economics Letters 73, 375-378.

Timmermann, A., (1995). "Co-integration tests of present vlaue models with a timevarying discount factor”, Journal of Applied Econometrics 10, 17-31.

West, K., (1988). “Dividend Innovations and Stock Price Volatility”, Econometrica $56,37-61$.

Zipf, G. K., (1949). "Human Behavior and the principle of least effort”, AddisonWesley. 